\title{
Spectroscopic Signature and Structure of the Active Sites in Ziegler-Natta Polymerization Catalysts revealed by Electron
} Paramagnetic Resonance

\author{
A. Ashuiev $^{1 \$}$, M. Humbert ${ }^{2 \$}$, S. Norsic ${ }^{2}$, J. Blahut ${ }^{3,4 \dagger}$, D. Gajan ${ }^{3}$, K. Searles ${ }^{1,5 \dagger}$, D. Klose ${ }^{1}$, A. \\ Lesage $^{3}$, G. Pintacuda ${ }^{3}$, J. Raynaud ${ }^{2^{*}}$, V. Monteil ${ }^{2^{*}}$, C. Copéret ${ }^{1^{*}}$, G. Jeschke ${ }^{1^{*}}$ \\ ${ }^{1}$ Department of Chemistry and Applied Biosciences, ETH Zurich, Wolfgang-Pauli-Strasse 1-5, 8093 \\ Zurich, Switzerland. \\ ${ }^{2}$ Université de Lyon, Univ. Lyon 1, CPE Lyon, CNRS, UMR 5128 - CP2M (Catalysis, Polymerization, \\ Processes \& Materials), PolyCatMat team, 43 Bd du 11 novembre 1918, 69616 Villeurbanne, France. \\ ${ }^{3}$ Univ Lyon, ENS Lyon, Université Lyon 1, CNRS, High-Field NMR Center of Lyon, UMR 5082, 5 rue \\ de la Doua, 69100 Villeurbanne, France.
}

Keywords: Ziegler-Natta • active sites $•$ EPR $\bullet$ hyperfine spectroscopy • polymerization mechanism • ethylene polymerization

\begin{abstract}
Despite decades of extensive studies, the atomic-scale structure of the active sites in heterogeneous Ziegler-Natta (ZN) catalysts, one of the most important processes of the chemical industry, remains elusive and a matter of debate. In the present work, the structure of "active sites" of ZN catalysts in the absence of ethylene, referred to as "dormant active sites", is elucidated from magnetic resonance experiments, carried out on samples reacted with increasing amounts of $\mathrm{BCl}_{3}$ so as to enhance the concentration of active sites and observe clear spectroscopic signatures. Using EPR and NMR spectroscopies, in particular 2D HYSCORE experiments complemented by DFT calculations, we show that the activated $\mathrm{ZN}$ catalysts contain bimetallic alkyl-Ti(III),Al species whose amount is directly linked to the polymerization activity of $\mathrm{MgCl}_{2}$-supported Ziegler-Natta catalysts. This connects those spectroscopic signatures to the active species formed in the presence of ethylene, and enables us propose an ethylene polymerization mechanism on the observed bimetallic alkyl-Ti(III),Al species based on DFT computations.
\end{abstract}

\section{Introduction}

Nowadays, polymers and particularly plastics are the most common products of chemical industry, comprising nearly $80 \%$ of the worldwide industry output. ${ }^{1}$ Two important polymers, which are widely used for e.g. packaging and construction materials in modern times, are polyethylene and polypropylene; they together sum up to more than half of the total plastics production. ${ }^{2}$ Such mass production of polyethylene and polypropylene became possible only after discovery of transition metal-based catalysts in the second half of the 20th century, such as Ziegler-Natta catalysts. ${ }^{3,4}$ With their ability to promote the synthesis of high-density linear polyethylene and stereoregular polypropylene under relatively mild conditions, the Ziegler-Natta catalysts are responsible nowadays for nearly $50 \%$ of worldwide production of polyethylene and around $95 \%$ of overall polypropylene production. ${ }^{5}$ The boom of their commercial usage arose with the development of heterogeneous $\mathrm{MgCl}_{2}$-supported Ziegler-Natta catalysts $\left(\mathrm{TiCl}_{4} / \mathrm{MgCl}_{2}\right.$ activated with $\mathrm{Et}_{3} \mathrm{Al}$ ) in the 1960s, which appeared to be 
nearly 100 times more active than the ones originally discovered by Ziegler and Natta. ${ }^{5,6}$ Due to the enormous productivity of such catalysts and their unprecedented ability to tune the properties of produced polymers in a controlled way, the supported Ziegler-Natta catalysts became a workhorse of modern polyolefin industry. ${ }^{6}$

Knowledge of the structure of the corresponding active sites represents a crucial step for enabling further improvement of the Ziegler-Natta catalytic process. However, despite decades of extensive studies, the atomic-scale description of the catalyst active sites (without or with coordinated monomer) remained so far elusive. Ziegler-Natta catalysts are typically prepared by impregnating an $\mathrm{MgCl}_{2}$ support with $\mathrm{TiCl}_{4}$ that needs to be first treated either mechanically (grinding/ball milling) or chemically with Lewis bases of different types, often oxygenbased such as diethers, alcohols, or THF. ${ }^{6,7}$ The catalytic Ziegler-Natta polymerization then requires the activation of the obtained precatalyst with an alkylaluminium reagent acting as a cocatalyst, e.g. $\mathrm{Et}_{3} \mathrm{Al}$. According to the proposition of Cossee and Arlman, ${ }^{8}$ the active site shall include a metal-carbon bond in order to perform ethylene insertion, which points towards $\mathrm{Ti}$ alkyl species as the active centers; alkylation of $\mathrm{TiCl}_{4}$ most likely occurs upon addition of aluminum alkyls (Fig. 1).

Based on the activity of homogeneous and supported group IV transition-metal metallocenes towards ethylene polymerization, ${ }^{9-12}$ for which cationic M(IV) alkyl species are the proposed active sites, ${ }^{13} \mathrm{Ti}(\mathrm{IV})$ cationic alkyls (A, Fig. 1a) are also thought as possible active species of $\mathrm{MgCl}_{2}$-supported Ziegler-Natta catalysts. ${ }^{14}$ On the other hand, the addition of aluminum alkyls leads to a reduction of a large amount of Ti(IV). ${ }^{15}$ Based on the estimated correlation of polymerization activity with the general amount of $\mathrm{Ti}^{3+}$ species, ${ }^{16} \mathrm{Ti}(\mathrm{III})$ alkyls (B, Fig. 1a) have been proposed to be the active species. ${ }^{17}$ This proposition is further supported by a recent finding that well-defined Ti(III) neutral alkyls are efficient ethylene polymerization catalysts, where the presence of an unpaired electron favors $\mathrm{C}_{2} \mathrm{H}_{4}$ polymerization when compared to their $\mathrm{Ti}(\mathrm{IV})$ analogues,${ }^{18}$ and by the activity of silicasupported $\mathrm{Ti}$ (III) hydrides towards ethylene polymerization. ${ }^{19,20}$ In fact, Giulio Natta himself proposed that the Ziegler-Natta catalysts could be bimetallic $\mathrm{Ti}(\mathrm{III})$-Al complexes containing organometallic bonds ${ }^{21}$ that could be interpreted as $\mathrm{Ti}(\mathrm{III})-\left(\mu_{2}-\mathrm{Cl}\right)-\left(\mu_{2}-\mathrm{R}\right)-\mathrm{AlR}_{2}$ type (C, Fig. 1a); the mechanism of formation of such bimetallic species after reaction with $\mathrm{Et}_{3} \mathrm{Al}$ was previously assessed using DFT computations. ${ }^{22}$ This structure is also the cornerstone of the Rodriguez-Van Looy mechanism, ${ }^{23}$ which extends upon Cossee \& Arlman's and proposes a bimetallic species to explain the stereospecificity of ZN-catalysed propylene polymerization. ${ }^{23}$ So far, however, there has been no direct evidence for any of these proposed structures.

The difficulty of spectroscopic characterization of the active species of heterogeneous ZieglerNatta catalysts or a "dormant" state, formed after activation but in the absence of the olefin monomer, is mostly related to the small amounts of those sites compared to the overall $\mathrm{Ti}$ amount. This problem may be addressed by investigating catalysts treated with Lewis acid co-activators, e.g. $\mathrm{BCl}_{3}$ (Fig. 1b), which has been shown to significantly enhance the catalytic activity due to an increased number of active sites, ${ }^{24,25}$ thereby opening the opportunity to capture spectroscopic signatures. Here, we report the structural characterization by EPR and NMR spectroscopies of these highly active ZieglerNatta catalysts for ethylene polymerization treated with different amounts of $\mathrm{BCl}_{3}$, and we evidence the spectroscopic signature of the "dormant" active sites after activation with $\mathrm{Et}_{3} \mathrm{Al}$ in the absence of ethylene in all cases, including when no boron activator is used. These sites correspond to bimetallic Ti(III),Al organometallic species that polymerize ethylene without the need of an additional activation step (addition of extra $\mathrm{Et}_{3} \mathrm{Al}$ ). Figure $1 \mathrm{~b}$ shows schematically the protocol used to prepare the $\mathrm{ZN}$ samples used in this study. 
a

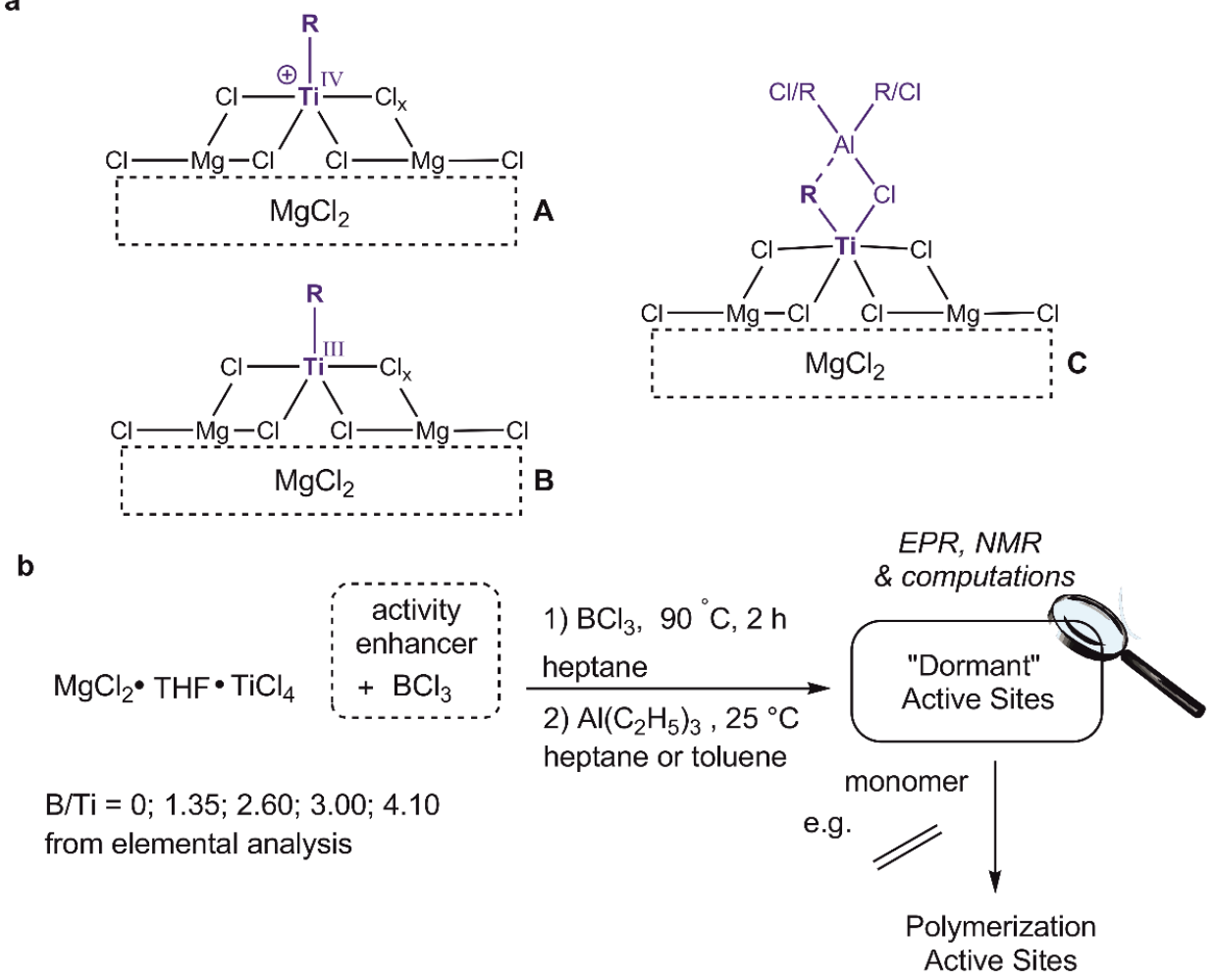

Figure 1. Overview of heterogeneous Ziegler-Natta (ZN) ethylene polymerization catalysis. (a) Possible active centers $(\mathbf{A})-(\mathbf{C})$ of $\mathrm{MgCl}_{2}$-supported ZN catalysts. (b) Preparation of $\mathrm{MgCl}_{2}$-supported $\mathrm{ZN}$ catalysts as studied in the present work.

\section{Results and Discussion \\ Spectroscopic identification of the "dormant" active species.}

As previously observed ${ }^{25}$ the addition of $\mathrm{BCl}_{3}$ continuously increases the activity of the ZieglerNatta catalyst from $12 \mathrm{~kg}_{\mathrm{PE}} \cdot\left(g_{\mathrm{cat}} \cdot h\right)^{-1}$ up to the maximal value of $38 \mathrm{~kg}_{\mathrm{PE}} \cdot\left(\mathrm{g}_{\mathrm{cat}} \cdot \mathrm{h}\right)^{-1}$ (Fig. 2a and Table S1). At the same time, the average molar masses $M_{\mathrm{n}}$ and $M_{\mathrm{w}}$ as well as the corresponding dispersity $\boxminus$ of produced polyethylene remain essentially the same upon $\mathrm{BCl}_{3}$ addition. A very minor decrease of dispersity $\boxminus$ with $\mathrm{BCl}_{3}$ addition, also observed for Ziegler-Natta catalysts with lower Ti loading even before $\mathrm{BCl}_{3}$ addition, ${ }^{24,25}$ is likely related, if significant, to the improvement of the surface properties of $\mathrm{MgCl}_{2}$ leading to a slightly more homogeneous environment of the active sites. This is strong evidence that the structure of the active species of the Ziegler-Natta catalysts is not changed and that the active-site concentration increases with addition of $\mathrm{BCl}_{3}$, as discussed in a previous investigation based on a combination of kinetics and polymerization results. ${ }^{25}$ The activation by $\mathrm{Et}_{3} \mathrm{Al}$ of samples prepared with different $\mathrm{BCl}_{3}$ loading (Fig. 1b) was studied by NMR and pulse
EPR spectroscopies (see SI Part 1). A low $[\mathrm{Al}] /[\mathrm{Ti}]$ ratio $(\sim 10)$, ca. one order of magnitude lower than typical ratios employed in ZNcatalysed polymerizations $-100<[\mathrm{Al}] /[\mathrm{Ti}]<$ $400,{ }^{25}$ - was used for these experiments for practicality. Higher ratios are used for conventional polymerization runs to scavenge impurities from the reaction medium (present in monomers, solvents, etc.) and to maintain high activities throughout the polymerization processes. To ensure that the observed spectroscopic signatures are actually associated with species related to the active sites, we verified that all alkylated materials prepared under the conditions used for the NMR and EPR experiments also displayed the expected polymerization performances (for details, see SI Parts 1.5, 1.9 \& 2.1, and Table S2).

We first investigated the samples via solidstate NMR. While the ${ }^{11} \mathrm{~B}$ solid-state NMR spectrum of precatalysts (before $\mathrm{Et}_{3} \mathrm{Al}$ addition) shows that all B-containing species are boron alkoxides, resulting from the reaction of $\mathrm{BCl}_{3}$ with either THF or chlorobutanoxy ligands, ${ }^{7}$ a sharp signal associated with physisorbed triethylboron formation $\left(\mathrm{BEt}_{3}\right)$ is observed after activation with $\mathrm{Et}_{3} \mathrm{Al}$ (see Fig. S1). The addition of $\mathrm{Et}_{3} \mathrm{Al}$ also 
leads to the appearance of paramagnetic signals at ca. $-60 \mathrm{ppm}$ in the ${ }^{1} \mathrm{H}$ solid-state NMR spectra $^{26}$ of Ziegler-Natta catalysts prepared with or without $\mathrm{BCl}_{3}$ addition, that are likely related to the presence of $\mathrm{Ti}^{\mathrm{III}}$ species in their vicinity (Fig. $\mathrm{S} 1, \mathrm{~d}, \mathrm{e})$. These paramagnetic signals are noticeably more pronounced in the spectra of the $\mathrm{BCl}_{3}$-treated samples (Fig. S1, e).

Consequently, we tried to identify these paramagnetic species by EPR spectroscopy at $10 \mathrm{~K}$ and $9.5 \mathrm{GHz}$ on samples with different $\mathrm{BCl}_{3}$ loadings, i.e. $\mathrm{B} / \mathrm{Ti}=0,2.60$ and 4.10 (Fig. 2b). These spectra reveal two paramagnetic species, characterized by a broad line around 340-390 $\mathrm{mT}$ and a narrower line at 320-340 $\mathrm{mT}$ that corresponds to an axially symmetric species. A species with a signal very similar to the $340-390$
$\mathrm{mT}$ band has been observed before and has been assigned to $\mathrm{Ti}(\mathrm{III})$ surface species on $\mathrm{MgCl}_{2}{ }^{27}$. Only the $320-340 \mathrm{mT}$ band grows with increasing amount of added $\mathrm{BCl}_{3}$, but is already present as a weak signal even in the absence of $\mathrm{BCl}_{3}$ (see Fig. 2c and Figs. S2 \& S3). Each of the three CW EPR spectra, shown in Fig. 2b, was fitted by a superposition of four individual spectra, revealing nearly the same $g$ tensor parameters for all samples (Table S3). Three mean sets of principal $g$ values contributing to the $340-390 \mathrm{mT}$ band are $g_{1}=[1.81671 .8657$ 1.9156], $g_{2}=\left[\begin{array}{lll}1.8910 & 1.9402 & 1.9621\end{array}\right], g_{3}=$ [1.9642 1.9716 1.9902]. They are consistent with previously estimated $g$ tensor parameters for the three different conformations of $\mathrm{TiCl}_{3}$ on the different $\mathrm{MgCl}_{2}$ surfaces. ${ }^{27}$
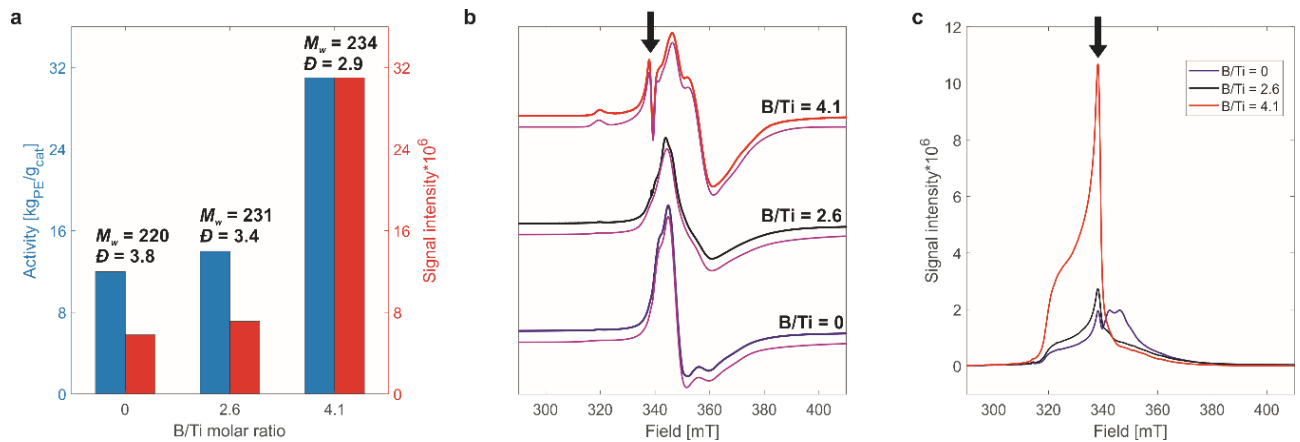

Figure 2. Polymerization Activity and EPR spectroscopic signature of "dormant" active sites. (a) Change of activities towards ethylene polymerization (blue, right scale) and $9.5 \mathrm{GHz}$ echo-detected EPR signal intensities (red, left scale) of Ziegler-Natta catalysts with a change of B/Ti ratio. For each catalyst, the average molar mass $M_{\mathrm{w}}\left[\mathrm{kg} \cdot \mathrm{mol}^{-1}\right]$ and the dispersity $\oslash=M_{\mathrm{w}} / M_{\mathrm{n}}$ of produced polyethylene are indicated. EPR signal intensities are measured at the field positions, marked with arrow in c, and normalized by the ratio of activity to intensity for the catalyst with $\mathrm{B} / \mathrm{Ti}=4.1$. (b) $9.5 \mathrm{GHz} \mathrm{CW}$ EPR spectra of Ziegler-Natta catalysts with $\mathrm{B} / \mathrm{Ti}=0$ (blue), $\mathrm{B} / \mathrm{Ti}=2.6$ (black) and $\mathrm{B} / \mathrm{Ti}=4.1$ (red), together with the simulations (violet) of all the shown spectra (see text for parameters of the simulations). (c) $9.5 \mathrm{GHz}$ echo-detected EPR spectra of Ziegler-Natta catalysts with $\mathrm{B} / \mathrm{Ti}=0$ (blue), $\mathrm{B} / \mathrm{Ti}=2.6$ (black) and $\mathrm{B} / \mathrm{Ti}=4.1$ (red). The signal that grows with increasing amount of added $\mathrm{BCl}_{3}$ is indicated with arrows in $\mathbf{b}$ and $\mathbf{c}$.

We then focused on establishing the nature of such species with the nearly axially symmetric $g$ tensor $g_{4}=[2.00232 .00532 .1289]$. Being larger than or similar to the free electron $g$ value $\left(g_{\mathrm{e}}\right)$, these principal $g$ values are highly unusual for a $\mathrm{Ti}(\mathrm{III})$ species. However, the observed $g$ tensor principal values are not consistent with other kinds of radical species. For instance, for the $\mathrm{O}_{2}$ radical species, previously observed in $\mathrm{MgCl}_{2}-$ supported Ziegler-Natta system, contacted with $\mathrm{O}_{2}{ }^{27}$ the $g$ tensor principal values were found to be not larger than 2.0209, with an anisotropy $\Delta g$ $=g_{\mathrm{z}}-g_{\mathrm{e}}$ nearly 7 times smaller than the one of the observed species. Also, rather short $T_{1}$ and
$T_{2}$ relaxation times (see Fig. S4) are more typical for the metal centers than for the radicals. ${ }^{28}$ In fact, $g$ tensors with unexpectedly large principal values $g>g_{\mathrm{e}}$ are sometimes observed experimentally for $3 d^{1}$ metal complexes, one example being the previously identified ${ }^{29} \mathrm{~V}(\mathrm{IV})$ 3,10,17,24-tetrasulphonatophthalocyanin (tspc) complex $[\mathrm{VO}(\mathrm{tspc})]^{2+}$ where ${ }^{59} \mathrm{~V}$ hyperfine coupling proves localization of the spin at the metal center; for this complex, DFT calculations on a well-defined structure (see Fig. S5 \& SI Part 2.6) provide $g=$ [2.0084 2.0096 2.1310], with all the principal values higher than $g_{\mathrm{e}}$ and close to the ones observed experimentally in the present 
work. This led us to attribute the observed species to a Ti(III) complex with a distinct electronic structure rather than to $\mathrm{O}_{2}{ }^{-}$or organic radicals. We found that this species was strongly suppressed in $35.7 \mathrm{GHz}$ pulse EPR echodetected spectra (Fig. S2), whereas it was readily observed in $9.5 \mathrm{GHz}$ echo-detected EPR spectra (Fig. 2c). In previous work a similar species (see Fig. S2) can be recognized as a weak contribution to Q-band EPR spectra that were obtained on catalysts that were not activated by $\mathrm{BCl}_{3} \cdot{ }^{27}$ Since strong suppression of the $\mathrm{TiCl}_{3}$ echo signals at $9.5 \mathrm{GHz}$ is beneficial for characterizing the $g>2$ species, further pulse EPR studies of the samples of $\mathrm{MgCl}_{2}$-supported Ziegler-Natta catalysts with different $\mathrm{BCl}_{3}$ loading were performed at this frequency (Fig. 2c). Like the CW EPR of this species, the echo-detected EPR signal, shown in Fig. 2c, continuously grew in intensity with increasing $\mathrm{BCl}_{3}$ loading and thus paralleled the increasing catalyst activity (Fig.
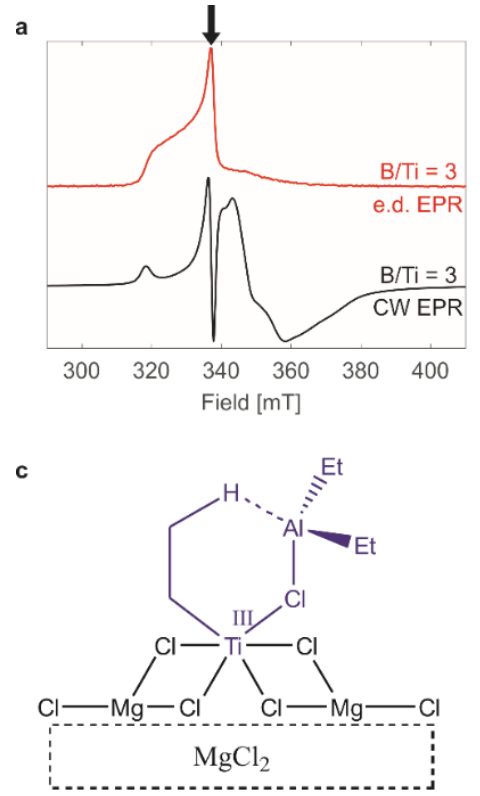

2a). Therefore, we identify this $g>2$ species (Fig. 2 b \& c, marked with arrows) as related to the active species in $\mathrm{MgCl}_{2}$-supported ZieglerNatta catalysts. The correlation between polymerization activity and this EPR signature strongly supports that the associated species is related to active sites formed in the presence of ethylene, hence it will be referred to as the "dormant" active sites.

Structure evaluation of the "dormant" active sites.

We further characterized this species by the 2D hyperfine spectroscopy technique HYSCORE. ${ }^{30}$ For these studies, we selected the sample with the highest activity of 38 $\mathrm{kg}_{\mathrm{PE}} \cdot\left(\mathrm{g}_{\mathrm{cat}} \cdot \mathrm{h}\right)^{-1}(\mathrm{~B} / \mathrm{Ti}=3$, see Table $\mathrm{S} 1)$ because of the presence of the highest concentration of the "dormant" active sites. The HYSCORE spectrum was measured at the maximum of the $9.5 \mathrm{GHz}$ field-swept echo-detected EPR spectrum (Fig. 3a, marked with arrow).
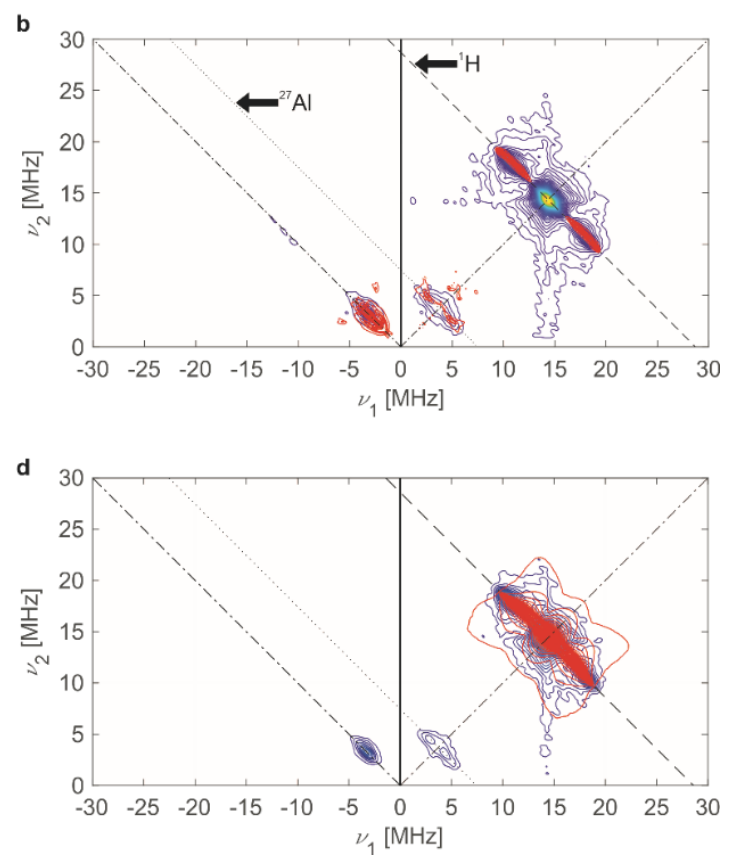

Figure 3. Structure and environment of the "dormant" active sites. (a) $9.5 \mathrm{GHz} \mathrm{CW}$ (black) and echodetected (red) EPR spectra of Ziegler-Natta catalyst with $\mathrm{B} / \mathrm{Ti}=3$. (b) Experimental 9.5 GHz HYSCORE spectrum of Ziegler-Natta catalyst with $\mathrm{B} / \mathrm{Ti}=3, \mathrm{~T}=\left[\begin{array}{lll}128 & 160 & 192\end{array}\right] \mathrm{ns}$ (blue to yellow), measured at $10 \mathrm{~K}$, together with simulation (red). (c) Proposed structure of the "dormant" active sites of heterogeneous Ziegler-Natta catalysts (see also Fig. S11, a). (d) Experimental HYSCORE spectrum of Ziegler-Natta catalyst with $\mathrm{B} / \mathrm{Ti}=3$ (blue) and simulation of experimental ${ }^{1} \mathrm{H}$ hyperfine couplings (green), based on DFT calculations on the proposed structure (see text \& Fig. S11, b - f). The experimental HYSCORE spectrum (see also Figs. S6 \& S7) was measured at the magnetic field position indicated by an arrow in a.

HYSCORE spectroscopy (Fig. 3b \& Fig. S6) reveals the presence of ${ }^{1} \mathrm{H}$ and ${ }^{27} \mathrm{Al}$ nuclei, coupled to the paramagnetic center by magnetic hyperfine interaction. The experimental HYSCORE pattern was simulated by adjusting hyperfine and quadrupole coupling parameters (Fig. 3b, red). The estimated ${ }^{1} \mathrm{H}$ isotropic hyperfine coupling of $a_{\text {iso }}\left({ }^{1} \mathrm{H}\right)=-7.5 \pm 0.5 \mathrm{MHz}$ is, in fact, typical for the protons of alkyl ligands in $\mathrm{Ti}(\mathrm{III})$ alkyl complexes. ${ }^{18,20}$ Within the point-dipole 
approximation we find a relatively large average $\mathrm{Ti} \cdots \mathrm{H}$ distance of $\mathrm{r}_{\mathrm{Ti}-\mathrm{H}}=3.16 \pm 0.24 \AA$, which suggests the presence of hydrogens in a close contact with $\mathrm{Ti}(\mathrm{III})$, such as $\alpha$ - or $\beta-\mathrm{H}$ agostic interactions (vide infra for further discussions). ${ }^{18,20}$ At the same time, the moderate ${ }^{27} \mathrm{Al}$ isotropic hyperfine coupling $a_{\text {iso }}\left({ }^{27} \mathrm{Al}\right)=1.5 \pm$ $0.2 \mathrm{MHz}$ indicates that the $\mathrm{Al}$ atom is in a proximity to the paramagnetic center, most likely being connected to it through one bridging atom (see also SI Part 2.8). Strong ${ }^{27} \mathrm{Al}$ quadrupole coupling $P\left({ }^{27} \mathrm{Al}\right)=-42 \pm 1 \mathrm{MHz}$ indicates low symmetry of the Al coordination geometry. No ${ }^{11} \mathrm{~B}$ hyperfine couplings were observed in the HYSCORE spectra. This is consistent with the absence of any modifications of the active site upon $\mathrm{BCl}_{3}$ addition that can be inferred from the similar features of the produced polyethylenes as previously mentioned, ${ }^{25}$ from the removal of $B$ in the form of $\mathrm{BEt}_{3}$ and from the unchanged $\mathrm{g}$ tensor principal values. Therefore, boron is not incorporated into the structure of these species, so that the addition of $\mathrm{BCl}_{3}$ has only an indirect influence onto their formation. The EPR data also agrees with the NMR data discussed above, namely the observation of ${ }^{1} \mathrm{H}$ paramagnetic NMR resonances (see Fig. S1). Very importantly, all these materials with characteristic EPR Ti(III)alkyl signatures are active in polymerization by sole addition of ethylene monomers (see Table S2). These EPR spectroscopic signatures are thus assigned to "dormant" active sites that generate the active species upon addition of ethylene. Notably, this species is observed in all materials including those without treatment with $\mathrm{BCl}_{3}$, reported here and previously, ${ }^{27}$ further indicating that this unique bimetallic $\mathrm{Ti}(\mathrm{III}), \mathrm{Al}$ structure is relevant to a broad range of ZieglerNatta catalysts.

Based on these conclusions, we performed a search through possible DFT-computed models, including $\mathrm{Ti}(\mathrm{III})$ alkyls, bridging alkyls and alkoxides with various ways of coordination of indicated organometallic ligands and aluminum alkyls (Figs. S8 - S11). For this purpose, DFTbased geometry optimizations, followed by calculation of EPR parameters (see SI Parts 1.17 - 1.18), were performed for the Ti(III) species, adsorbed on an $\mathrm{MgCl}_{2}$ (110) surface; this surface was previously found to be stabilized by the presence of Lewis bases over an alternative (104) cut, $^{31}$ and was also shown to be preferential for the binding of titanium species. ${ }^{32}$ Among all the tested models, we found only one
(Fig. 3c \& Fig. S11, a), that provides DFTcalculated ${ }^{1} \mathrm{H}$ hyperfine couplings for all $\mathrm{H}$ atoms of the $\mathrm{Ti}_{-} \mathrm{C}_{2} \mathrm{H}_{5}$ ligand that are in line with the experimental ${ }^{1} \mathrm{H}$ HYSCORE pattern (Fig. 3d \& Fig. $S 11, b-f)$, together with a reasonable fit of the DFT-computed ${ }^{27} \mathrm{Al}$ couplings to the ones observed experimentally (Table S4). As ${ }^{1} \mathrm{H}$ hyperfine couplings were previously found to act as fingerprints of the conformations of $\mathrm{Ti}(\mathrm{III})$ alkyl complexes, ${ }^{18,20}$ we propose the structure, shown in Fig. 3c, as the "dormant" active sites of the Ziegler-Natta catalysts. Being essentially a $\mathrm{Ti}(\mathrm{III})$ metal-alkyl complex of a formula $\left[\mathrm{Ti}\left(\mathrm{C}_{2} \mathrm{H}_{5}\right) \mathrm{Cl}_{2}-(\mu\right.$ Cl)-Al $\left.\left(\mathrm{C}_{2} \mathrm{H}_{5}\right)_{2}\right] @ \mathrm{MgCl}_{2}$ (Fig. 3c \& 1, Fig. 4), this structure is in fact in line with the original proposal of Giulio Natta regarding the active site of Ziegler-Natta catalysts. ${ }^{21}$ With a calculated Ti$\mathrm{C}-\mathrm{H}$ angle of $98.64^{\circ}$, it displays an $\alpha-\mathrm{H}$ agostic interaction; this indicates the presence of a weak $\pi$ character in the Ti-C bond. ${ }^{18,33}$ The Al atom is essentially tris-coordinated, except for a weak $\mathrm{Al}-\mathrm{H}$ interaction (2.183 $\AA$ distance) with the $\beta-\mathrm{H}$ atom of the $\mathrm{Ti}-\mathrm{C}_{2} \mathrm{H}_{5}$ ligand. A similar structure of $\left[\mathrm{TiCl}_{2}-(\mu-\mathrm{Cl})-\left(\mu-\mathrm{C}_{2} \mathrm{H}_{5}\right)-\mathrm{Al}\left(\mathrm{C}_{2} \mathrm{H}_{5}\right)_{2}\right] @ \mathrm{MgCl}_{2}(\mathbf{C}, \mathrm{Fig}$. 1a \& Fig. S9, b), proposed in previous computational work, ${ }^{22}$ which has the $\alpha-C$ atom of the $\mathrm{Ti}_{-} \mathrm{C}_{2} \mathrm{H}_{5}$ ligand bridging between the $\mathrm{Ti}$ and $\mathrm{Al}$ atoms, is calculated to be very close in energy to the one shown on Fig. $3 c(\Delta \mathrm{G}(\Delta \mathrm{H})=-1.7(-4.0)$ $\mathrm{kcal} / \mathrm{mol}$ ); however, it exhibits a strong mismatch between DFT-computed ${ }^{1} \mathrm{H}$ hyperfine couplings and the experimental HYSCORE spectrum (see Fig. S9, b). Note that the other possible structure, namely $\left[\mathrm{Ti}\left(\mathrm{C}_{2} \mathrm{H}_{5}\right) \mathrm{Cl}-\left(\mu_{2}-\mathrm{Cl}_{2}\right)-\mathrm{Al}\left(\mathrm{C}_{2} \mathrm{H}_{5}\right)_{2}\right] @ \mathrm{MgCl}_{2}$ with a 4-coordinated $\mathrm{Al}$ atom (Fig. S9, a), which should be formed after activation with $\mathrm{Et}_{3} \mathrm{Al}$ according to a previously proposed mechanism, ${ }^{22}$ was also dismissed due to a mismatch between calculated and experimental HYSCORE spectra (Fig. S9, a). Absence of such species in the Ziegler-Natta system could be explained by coordination of additional molecules of $\mathrm{Et}_{3} \mathrm{Al}$, which is present in excess in the system, to the $\mathrm{Cl}$ atoms of the $\mathrm{Ti}(\mathrm{III})$ "dormant" active site (Fig. 3c); this effect could be deduced from the previous observation of coordinated aluminum in a close proximity to the Ti center in EPR spectra of the surface $\mathrm{TiCl}_{3}$ species upon the addition of $\mathrm{O}_{2} \cdot{ }^{27}$ Overall, in view of a better match to the EPR parameters, the "dormant" active site is best described as the complex shown on Fig. $3 \mathrm{c}$, that is formed after activation with $\mathrm{Et}_{3} \mathrm{Al}$ by the previously proposed "direct transalkylation" mechanism. ${ }^{22}$ 


\section{Mechanism of ethylene polymerization}

DFT computations (see SI Parts 1.19, 2.9 \&

Fig. S12) show that in the presence of ethylene monomers, the "dormant" active site (Fig. $3 c$ \& 1 , Fig. 4a) can yield a m-ethylene complex $\left[\mathrm{Ti}\left(\mathrm{C}_{2} \mathrm{H}_{5}\right) \mathrm{Cl} \cdots\left(\mathrm{C}_{2} \mathrm{H}_{4}\right)-\left(\mu_{2}-\mathrm{Cl}_{2}\right)-\mathrm{Al}\left(\mathrm{C}_{2} \mathrm{H}_{5}\right)_{2}\right] @ \mathrm{MgCl}_{2}(1-$ $\mathrm{C}_{2} \mathrm{H}_{4}$, Fig. 4a; see also Fig. S13), which is rather close in energy to the "dormant" active site (Fig. 3c; $\Delta \mathrm{G}(\Delta \mathrm{H})=2.5(-8.8) \mathrm{kcal} / \mathrm{mol})$. Note that the coordination of ethylene on the "dormant" sites $\left(\mathbf{1}-\mathrm{C}_{2} \mathrm{H}_{4}\right.$, Fig. 4a) requires neither a vacancy in the coordination sphere of the active site, in contrast to previous propositions, ${ }^{23}$ nor decoordination of the $\mathrm{AlEt}_{2} \mathrm{Cl}$ fragment. ${ }^{22}$ Instead, one $\mathrm{Cl}$ atom of $\mathrm{MgCl}_{2}$ decoordinates, thus showing that the $\mathrm{MgCl}_{2}$ surface can be viewed as a hemilabile ligand.
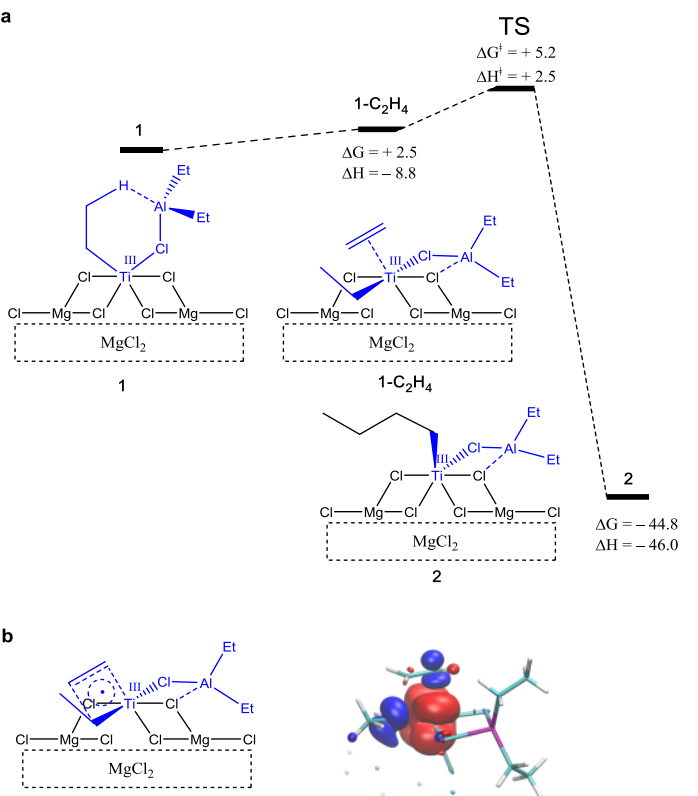

Figure 4. Ethylene polymerization pathways. (a) Relative enthalpies and Gibbs free energies of: 1, "dormant" active site (Fig. 3c) that is observed experimentally before ethylene addition; $\mathbf{1}-\mathrm{C}_{2} \mathrm{H}_{4}$, a $\pi$-ethylene complex; transition state (TS) of ethylene insertion; $\mathbf{2}$, product of ethylene insertion. (b) Structure of the TS (left), together with the calculated spin density distribution in it (right; red for positive, blue for negative spin density; contour level $0.1 \%$ ). All energies are given in $\mathrm{kcal} / \mathrm{mol}$.

After the formation of the r-ethylene complex, ethylene insertion appears to be nearly barrierless $\left(\Delta \mathrm{G}^{*}\left(\Delta \mathrm{H}^{*}\right)=5.2(2.5) \mathrm{kcal} / \mathrm{mol}\right)$. This is explained by a combination of two factors: i) the strong $\pi$ character in the $\mathrm{Ti}-\mathrm{C}$ bond of the $\pi-$ ethylene complex $\left(\mathbf{1}-\mathrm{C}_{2} \mathrm{H}_{4}\right.$, Fig. $\left.4 \mathrm{a}\right)$, which was previously discussed to be necessary for the olefin insertion into the metal-carbon bonds ${ }^{33}$ and was revealed by a deviation of the natural hybrid orbital (NHO) on carbon ${ }^{18,33}$ from the Ti-C axis in $1-\mathrm{C}_{2} \mathrm{H}_{4}\left(\Theta_{\mathrm{NHO}-\mathrm{C}-\mathrm{Ti}}=25.9^{\circ}\right)$, and ii) the delocalization of the unpaired electron in the transition state (TS) structure (Fig. 4b, left) that further stabilizes the $\mathrm{TS}^{18}$ and is evidenced by the calculated spin density distribution (Fig. 4b, right). Together, these two factors, earlier referred to as an "augmented" Cossee-Arlman mechanism ${ }^{18}$, strongly facilitate ethylene insertion after the formation of the m-ethylene complex in $d^{1} \mathrm{Ti}$ alkyls, compared to their $\mathrm{d}^{0}$ analogues. ${ }^{18}$. Therefore, the experimentally observed initial structure, referred to as "dormant" active site (1, Fig. 4a \& Fig. 3c), becomes the active site upon addition of ethylene through a loss of the $\mathrm{Al}-\mathrm{H}$ interaction and transformation into the structure with a 4coordinated $\mathrm{Al}$ atom, which is then followed by ethylene insertion, thus leading to polymer chain growth (Fig. 4). In fact, the product of ethylene insertion (2, Fig. 4a), essentially a Ti(III) alkyl complex with an $\mathrm{\alpha}-\mathrm{H}$ agostic interaction (the Ti$\mathrm{C}-\mathrm{H}$ angle is $97.79^{\circ}$ ), is structurally similar to the previously reported highly active well-defined $\mathrm{Ti}(\mathrm{III})$ alkyl species, which polymerize ethylene in the absence of co-catalysts. ${ }^{18}$ At the same time, the previously discussed Ti(III) alkyl species with 4-coordinated $\mathrm{Al}$ atom (Fig. S9, a), which are isostructural to the product 2 except for $-E t$ ligand instead of $-\mathrm{n}-\mathrm{Bu}$, are found to be also close by energy to the same TS, shown on Fig. 4 $\left(\left(\Delta \mathrm{G}^{*}\left(\Delta \mathrm{H}^{*}\right)=27.0(14.2) \mathrm{kcal} / \mathrm{mol}\right)\right.$. This ensures that the reaction of ethylene polymerization is continued after the formation of the product of the first $\mathrm{C}_{2} \mathrm{H}_{4}$ insertion (2, Fig. 4a) and involves the same mechanism, where a vacant site, needed to coordinate ethylene and for the subsequent polymerization, is generated by decoordination of a $\mathrm{Cl}$ atom from the hemilabile $\mathrm{MgCl}_{2}$ surface. While both structures $\mathbf{1}$ and $\mathbf{2}$ appear in line with the original proposition of Guilio Natta, ${ }^{21}$ as well as with the Rodriguez-Van Looy mechanism ${ }^{23}$, one should note again that the proposed mechanism does not require the presence of a vacant coordination site on Ti for olefin coordination and insertion.

\section{Conclusion}

We report the first observation of spectroscopic signatures of the "dormant" active sites of heterogeneous Ziegler-Natta catalysts 
characterized in the absence of ethylene, that can be attributed to bimetallic Ti(III),Al alkyl species (Fig. 3c). Towards this goal, we used $\mathrm{BCl}_{3}$ as an additive because it was shown to increase the amount of the active sites in $\mathrm{MgCl}_{2}$ supported Ziegler-Natta catalysts. ${ }^{25}$ These species, generated in the absence of ethylene readily produce polyethylene in the presence of ethylene, linking their spectroscopic signatures to the active sites of the Ziegler-Natta catalysts (Fig. 4). This opens a way to further experimental and computational studies of the Ziegler-Natta system, for example, of the influence of internal donors, adsorbed on the $\mathrm{MgCl}_{2}$ surface close to the proposed bimetallic Ti(III),Al sites, on the stereospecificity of propylene polymerization ${ }^{34,35}$ or on the concentration of the "dormant" active sites. ${ }^{36}$ This also enables further improvement of the productivity of Ziegler-Natta catalysts via a rational approach, based on the knowledge of the structure of the active sites.

\section{ASSOCIATED CONTENT}

\section{Supporting information}

This material is available free of charge via the Internet at http://pubs.acs.org

\section{AUTHOR INFORMATION}

\section{Corresponding authors}

* ccoperet@ethz.ch; gjeschke@ethz.ch; jean.raynaud@univ-lyon1.fr; vincent.monteil@univlyon1.fr

\section{Present addresses \\ ${ }^{4 \dagger}$ Faculty of Science, Charles University, Hlavova 8, 12842 Prague 2, Czech Republic \\ ${ }^{5 \dagger}$ University of Florida, Department of Chemistry, Gainesville Florida 32611-7200, USA}

\section{Author contributions}

$\$$ These authors contributed equally

\section{Acknowledgements}

We acknowledge Olivier Boyron, Manel Taam and Edgar Espinosa (Université de Lyon) for SEC analyses and Rene Tschaggelar (ETH Zürich) for the technical support in EPR experiments. A.A. is supported by a SNF-ANR grant (Mr. CAT 2-77275-15). M.H. is supported by an ANR-SNF grant (MRCAT ANR-15CE29-0025).

\section{REFERENCES}

(1) Singh, K. Chemistry, Economics and Politics. In Chemistry in Daily Life; PHI Learning Pvt. Ltd.: Delhi, Republic of India, 2012, pp. 132 - 134.

(2) Geyer, R.; Jambeck, J.R.; Law, K.L. Production, use, and fate of all plastics ever made. Sci. Adv. 2017, 3, e1700782.

(3) Ziegler, K.; Holzkamp, E.; Breil, H.; Martin, H. Das Mülheimer Normaldruck-Polyäthylen-Verfahren.

Angew. Chem. 1955, 67, 541 - 547.

(4) Natta, G. Kinetic studies of $\alpha$ - olefin polymerization. J. Polym. Sci. 1959, 34, $21-48$.

(5) Kashiwa, N. The discovery and progress of $\mathrm{MgCl}_{2}$ - supported $\mathrm{TiCl}_{4}$ catalysts. J. Polym. Sci. Part A 2004, 42, 1 - 8 .

(6) Cecchin, G.; Morini, G.; Piemontesi, F. Ziegler- Natta Catalysts. In Kirk-Othmer Encyclopedia of Chemical Technology; John Wiley \& Sons: Hoboken, US, 2000; Vol. 26, pp. $502-554$.

(7) Grau, E.; Lesage, A.; Norsic, S.; Copéret, C.; Monteil, V.; Sautet, P. Tetrahydrofuran in $\mathrm{TiCl}_{4} / \mathrm{THF} / \mathrm{MgCl}_{2}$ : a Non-Innocent Ligand for Supported Ziegler-Natta Polymerization Catalysts. ACS Catal. 2013, 3, 52 - 56.

(8) Arlman, E.J.; Cossee, P. Ziegler-Natta catalysis III. Stereospecific polymerization of propene with the catalyst system $\mathrm{TiCl}_{3}-\mathrm{AlEt}_{3}$. J. Catal. 1964, 3, 99 - 104 (1964).

(9) Kaminsky, W. Highly active metallocene catalysts for olefin polymerization. J. Chem. Soc. 1998, 9, 1413 $-1418$.

(10) Jordan, R.F.; Dasher, W.E.; Echols, S.F. Reactive cationic dicyclopentadienyl zirconium(IV) complexes. J. Am. Chem. Soc. 1986, 108, 1718 - 1719.

(11) Marks, T.J. Surface-Bound Metal Hydrocarbyls. Organometallic Connections between Heterogeneous and Homogeneous Catalysis. Acc. Chem. Res. 1992, $25,57-65$.

(12) Olabisi, O.; Atiqullah, M.; Kaminsky, W. Group 4 Metallocenes: Supported and Unsupported. J. Macromol. Sci. Polymer Rev. 1997, 37, 519 - 554. (13) Jordan, R.F. Cationic Metal-Alkyl Olefin Polymerization Catalysts. J. Chem. Educ. 1988, 65, $285-289$.

(14) Kissin, Yu.V. Active centers in Ziegler-Natta catalysts: Formation kinetics and structure. J. Catal. 2012, 292, 188 - 200.

(15) Fregonese, D.; Mortara, S.; Bresadola, S. ZieglerNatta $\mathrm{MgCl}_{2}$-supported catalysts: relationship between titanium oxidation states distribution and activity in olefin polymerization. J. Mol. Catal. A: Chemical 2001, $172,89-95$.

(16) Koshevoy, E.I.; Mikenas, T.B.; Zakharov, V.A.; Volodin, A.M.; Kenzhin, R.M. Formation of isolated titanium(III) ions in superactive titanium-magnesium catalysts with a low titanium content as active sites in ethylene polymerization. Catal. Comm. 2014, 48, 38 40.

(17) Koshevoy, E.I.; Mikenas, T.B.; Zakharov, V.A.; Shubin, A.A.; Barabanov, A.A. Electron Paramagnetic Resonance Study of the Interaction of Surface Titanium Species with $\mathrm{AlR}_{3}$ Cocatalyst in Supported 
Ziegler-Natta Catalysts with a Low Titanium Content. J. Phys. Chem. C 2016, 120, 1121 - 1129.

(18) Ashuiev, A.; Allouche, F.; Wili, N.; Searles, K.; Klose, D.; Copéret, C.; Jeschke, G. Molecular and Supported Ti(III)-Alkyls: Efficient Ethylene Polymerization Driven by $\pi$-Character of Metal-Carbon Bonds and Back Donation from a Singly Occupied Molecular Orbital. Chem. Sci. 2021, 12, 780 - 792. (19) Zakharov, V.A.; Yermakov, Yu.I. Supported Organometallic Catalysts for Olefin Polymerization. Catal. Rev. Sci. Eng. 1979, 19, 67 - 103.

(20) Allouche, F.; Klose, D.; Gordon, C.P.; Ashuiev, A.; Wörle, M.; Kalendra, V.; Mougel, V.; Copéret, C.; Jeschke, G. Low-Coordinated Ti(III) Alkyl-Molecular and Surface-Complexes: Detailed Structure from Advanced EPR Spectroscopy. Angew. Chem. Int. Ed. 2018, 57, 14533 - 14537.

(21) Natta, G., Pino, P., Mazzanti, G.; Gianini, U. A crystallizable organometallic complex containing titanium and aluminium. J. Am. Chem. Soc. 1957, 79, 2975 - 2976.

(22) Bahri-Laleh, N.; Correa, A.; Mehdipour-Ataei, S.; Arabi, H.; Haghighi, M.N.; Zohhuri, G.; Cavallo, L. Moving up and down the Titanium Oxidation State in Ziegler-Natta Catalysis. Macromolecules 2011, 44, $778-783$.

(23) Rodriguez, L.A.M.; Van Looy, H.M. Studies on Ziegler- Natta catalysts. Part V. Stereospecificity of the active center. J. Polym. Sci.: Part A-1 1966, 4, 1971 1992.

(24) Ribour, D.; Monteil, V.; Spitz, R. Strong activation of $\mathrm{MgCl}_{2}$ - supported Ziegler- Natta catalysts by treatments with $\mathrm{BCl}_{3}$ : Evidence and application of the "cluster" model of active sites. J. Polym. Sci. Part A 2009, 47, $5784-5791$.

(25) Humbert, M.; Norsic, S.; Raynaud, J.; Monteil, V. Activity enhancement of $\mathrm{MgCl}_{2}$-supported Ziegler-Natta catalysts by Lewis-Acid pre-treatment for ethylene polymerization. Chinese J. Polym. Sci. 2019, 37, 1031 $-1038$.

(26) Pell, A.J.; Pintacuda, G.; Grey, C.P. Paramagnetic NMR in solution and the solid state. Prog. Nucl. Mag.

Res. Sp. 2019, 111, 1 - 271.

(27) Morra, E.; Giamello, E.; Van Doorslaer, S.; Antinucci, G.; D'Amore, M.; Busico, V.; Chiesa, M. Probing the Coordinative Unsaturation and Local Environment of $\mathrm{Ti}^{3+}$ Sites in an Activated High-Yield
Ziegler-Natta Catalyst. Angew. Chem. Int. Ed. 2015, 54,4857 - 4860 .

(28) Schweiger, A.; Jeschke, G. Relaxation and related phenomena. In Principles of pulse electron paramagnetic resonance; Oxford University Press, New York, US, 2001, pp. 208 - 233.

(29) Skorobogaty, A.; Lancashire, R.; Smith, T.D.; Pilbrow, J.R.; Sinclaire, G.R. Optical and Electron Spin Resonance Studies of Copper(II), Nickel(II) and Oxovanadium(IV) Complexes of Water-soluble Phthalocyanine and Porphyrazine Chelates Absorbed on Sephadex Resins, and the Effect of Added Dithionite. J. Chem. Soc., Faraday Trans. 2 1983, 79, $1123-1141$.

(30) Höfer, P.; Grupp, A.; Nebenführ, H.; Mehring, M. Hyperfine sublevel correlation (hyscore) spectroscopy: a 2D ESR investigation of the squaric acid radical. Chem. Phys. Lett. 1986, 132, 279 - 282.

(31) Capone, F.; Rongo, L.; D’Amore, M.; Budzelaar, P.H.M.; Busico, V. Periodic Hybrid DFT Approach (Including Dispersion) to $\mathrm{MgCl}_{2}$-Supported ZieglerNatta Catalysts. 2. Model Electron Donor Adsorption on $\mathrm{MgCl}_{2}$ Crystal Surfaces. J. Phys. Chem. C 2013, $117,24345-24353$.

(32) Brambilla, L.; Zerbi, G.; Piemontesi, F.; Nascetti, $\mathrm{S}$.; Morini, G. Structure of $\mathrm{MgCl}_{2}-\mathrm{TiCl}_{4}$ complex in comilled Ziegler-Natta catalyst precursors with different $\mathrm{TiCl}_{4}$ content: Experimental and theoretical vibrational spectra. J. Mol. Catal. A Chem. 2007, 263, $103-111$. (33) Gordon, C.P.; Shirase, S.; Yamamoto, K.; Andersen, R.A.; Eisenstein, O.; Copéret, C. NMR chemical shift analysis decodes olefin oligo- and polymerization activity of $d^{0}$ group 4 metal complexes. Proc. Natl. Acad. Sci. 2018, 115, 5867 - 5876.

(34) Vittoria, A.; Meppelder, A.; Friederichs, N.; Busico, V.; Cipullo, R. Demystifying Ziegler-Natta Catalysts: The Origin of Stereoselectivity. ACS Catal. 2017, 7, $4509-4518$.

(35) Stukalov, D.V.; Zakharov, V.A.; Zilberberg, I.L. Adsorption Species of Ethyl Benzoate in $\mathrm{MgCl}_{2}-$ Supported Ziegler-Natta Catalysts. A Density Functional Theory Study. J. Phys. Chem. C 2010, 114, $429-435$.

(36) Podvorica, L.; Salvadori, E.; Piemontesi, F.; Vitale, G.; Morini, G.; Chiesa, M. Isolated Ti(III) Species on the Surface of a Pre-active Ziegler Natta Catalyst. Appl. Magn. Reson. 2020, 51, 1515 - 1528.

Table of Contents 
<smiles>C[Si]#[Si][Si]</smiles> 